\title{
El testamento literario de un antipoeta
}

\section{The Literary Testament of an Antipoet}

\section{Resumen}

En 2006 fue publicado Discursos de sobremesa, una colección de cinco discursos pronunciados por Nicanor Parra entre 1991 y 1997. El presente artículo propone leer aquellos textos como el testamento literario de su autor y la respuesta antipoética al proceso de "canonización" que representarían los premios y ceremonias para los que fueron preparados. Con dicho propósito, el estudio contempla la existencia de un corpus que trasciende la selección establecida por la edición de 2006 y analiza el testamento literario como una escritura arraigada en una larga tradición.

Palabras claves Nicanor Parra, discursos, testamento, antipoeta, performance.

\begin{abstract}
The book After-dinner Declarations published in 2006 is a selection of five speeches pronounced by Nicanor Parra between 1991 and 1997. This article set out into reading those texts as the Literary Testament of his author and the antipoetic response to "canonization" process it would symbolize the awards and ceremonies they were conceived for. In order to it, this study considers a corpus beyond the one established by the edition of 2006 and analyses Literary Testament as a traditional writing whose older samples go back into and old tradition.
\end{abstract}


En el año 1997, durante el acto de entrega del Premio "Luis Oyarzún” en Valdivia, Nicanor Parra pronunció un discurso titulado "Aunque no vengo preparrado". Desafiando la lógica del acto, el poeta subió al atril blandiendo los folios del texto que se disponía a leer haciendo uso de uno de sus clásicos juegos antipoéticos consistentes en mostrar abiertamente lo que se supone oculto, como la tachadura que sustituía "policía" por "poesía" en la colección de tarjetas postales de $1983^{1}$. En el referido discurso, tras ensartar una lista de anécdotas y recuerdos en torno a sus años en el INBA junto a Oyarzún y a sus encuentros con una incipiente neovanguardia en Santiago -interrumpidas, a veces, por sus alegatos ecologistas-, el poeta cerró su intervención con una fórmula que sonaba a despedida: "Última vez que me presento en público". Pronunciada con un tono de congoja que contrastaba con el sentido del humor que había caracterizado sus apariciones públicas, la frase insinuaba una retirada.

El texto de aquella intervención fue publicado una década después junto a otros cuatro discursos pronunciados durante la década de $1990^{2}$ cuando el poeta frisaba la edad de ochenta años. Cada uno de aquellos textos representaba la respuesta a un acto de homenaje a la trayectoria del poeta que se había definido como "antipoeta": "Mai Mai Peñi. Discurso de Guadalajara" (1991) fue leído durante la ceremonia de entrega del I Premio Internacional de Literatura Latinoamericana y del Caribe Juan Rulfo, "Happy birthday. Discurso del Caupolicán" (1993) fue el discurso inaugural del Festival Teatro de las Naciones celebrado ese año en Santiago, “Also Sprach Altazor” (1993) fue preparado para la celebración del centenario de Vicente Huidobro y "Discurso del Bío Bío" (1996) fue la respuesta a la asignación del doctorado Honoris Causa por la Universidad de Concepción. Aquellos cinco textos volvieron a ser reproducidos cinco años después

${ }^{1}$ Chistes parfa desorientar a la policía poesía. Segunda edición. Galería Época y Universidad Federico Santa María, 1983.

${ }^{2}$ Nicanor Parra. Discursos de sobremesa. Ediciones Universidad Diego Portales, 2006. Esta no fue la primera edición de estas características. Le había precedido una publicación fallida (Nicanor Parra. Discursos de sobremesa. Edición de Mario Rodríguez. Cuadernos Atenea, 1997), retirada de la circulación por voluntad del poeta. 
en el segundo volumen de las obras completas del poeta. En esta ocasión, los editores incorporaron como material adicional otros tres discursos inmediatamente posteriores, de similares características textuales y producidos con la misma intención protocolaria: "Talca, Chillán, Londres. Un discurso que está x escribirse" (1998) fue leído durante el acto de recepción de la Medalla al Mérito Juan Ignacio Molina en la Universidad de Talca, "Gracias muchas. El discurso que está por escribirse" (1999), en la ceremonia de inauguración del año académico de la Universidad de Chile donde fue condecorado con la Medalla Rectoral y "No me explico señor rector" (2001), durante el acto de entrega del Premio Bicentenario ${ }^{3}$. Aunque presentados como "borradores", todo lleva a pensar que forman parte de un mismo proyecto literario en torno a la oratoria pública y arraigado en los Sermones y prédicas del Cristo de Elqui (1977 y 1979).

Aunque las apariciones posteriores a 1997 desmentían parcialmente la frase pronunciada en Valdivia, daban continuidad a una práctica consistente en responder irónicamente a los homenajes que se le ofrecían en un momento de su trayectoria en el que el autodeclarado "antipoeta" se debatía entre aquella imagen trasgresora, los "laureles" de la academia y el declarado deseo de un retiro definitivo: “Basándome en esta filosofía [Código de Manú] me retiré -algo tarde, con más de ochenta años- al bosque, en la costa chilena. Ahora vivo entre Cartagena y la Isla Negra, en un lugarejo que se llama Las Cruces, entre Pablo Neruda y Vicente Huidobro" (Cit. en Binns et al.).

Los textos de los ocho discursos pronunciados entre 1991 y 2001 coincidían, desde un punto de vista pragmático, en su condición protocolaria $\mathrm{y}$, desde un punto de vista temático, en representar la voz de un antipoeta anciano, obsesionado con los premios y con la inminencia de la muerte. En el discurso de 1991, Parra anticipaba: "Discurso de Guadalajara/ afonía total/ Huelo + a cipreses que a

\footnotetext{
${ }^{3}$ Además de estos tres discursos, existen otros anteriores y posteriores que invitan a reconsiderar la nómina de 2006 y el alcance de este género producido durante la última etapa de exposición pública del poeta. Dado que en este trabajo nos proponemos únicamente ilustrar una dirección de lectura para estas obras, nos concentraremos en las ocho muestras editadas hasta la fecha.
} 
laureles" (586) ${ }^{4}$. Estas obsesiones se correspondían, por otra parte, con el proyecto paralelo que el poeta había emprendido en la década de 1980 de traducir Rey Lear ${ }^{5}$, la tragedia de un anciano que ve como sus herederos se reparten su reino antes de morir. Sobre este proyecto, Rafael Gumucio se preguntaba si a esa edad no hubiera sido más apropiado para Nicanor Parra dedicarse a ordenar sus papeles, escribir sus memorias y redactar un testamento (417). La pregunta que surge es: ¿no era eso lo que estaba haciendo al redactar sus discursos de sobremesa? En "Mai Mai Peñi”" afirma:

Estoy sentado al escritorio

A mi izquierda los manuscritos del último discurso malo

A mi derecha los del primer discurso bueno

Acabo de redactar una página

Mi problema es el siguiente

Dónde la deposito madre mía!

A la izquierda? a la derecha? (557)

Al alcanzar una edad avanzada y con una trayectoria dilatada como la de Nicanor Parra en la década de 1990 es frecuente que un escritor se vea abocado a que afrontar actos de reconocimiento o dedique sus esfuerzos a hacer memoria y poner en orden sus ideas y recuerdos para legar una imagen propia no expuesta a los arbitrios de terceras personas. Así lo hicieron Pablo Neruda (Confieso que he vivido, 1973), Rafael Alberti (La arboleda perdida, 1978-88) o Carlos Barral (Memorias, 1973-88), por citar tres ejemplos conocidos. Observados como una serie autónoma, los discursos de sobremesa representaron un proyecto capaz de

\footnotetext{
${ }^{4}$ Este artículo se propone abordar los discursos de sobremesa como partes de un macrotexto que se fue presentando por entregas ante el público. Los ocho textos que componen el corpus del análisis se editaron por separado y de algunos de ellos existen varias versiones. Hasta la fecha, la versión última y más fiable de cada uno de ellos es la incluida en Nicanor Parra. Obras completas \& algo + (1972-2006). II. Galaxia Gutenberg, 2011. En adelante, citaré estas obras según la versión contenida en dicha edición.

${ }^{5}$ Nicanor Parra. Lear, rey \& mendigo. Santiago: Ediciones Universidad Diego Portales, 2004.
} 
cumplir con una doble función: por una parte, responder al protocolo de las ceremonias en los que fueron leídos y, por otra parte, hacer balance de la trayectoria literaria e intelectual del poeta homenajeado.

A lo largo de este trabajo analizaremos estas obras como un testamento literario abundando en sus relaciones con un género tradicional de naturaleza satírica. El objetivo es llamar la atención sobre las evidentes coincidencias textuales y temáticas -quizás inconscientes- entre dicha tradición y el macrotexto ${ }^{6}$ creado por el autor de los antipoemas para "poner en escena" su despedida de la palestra literaria. Además abordaremos los discursos de sobremesa como la respuesta programada por el poeta para afrontar la contradicción que le asalta al tener que conjugar su imagen pública de antipoeta con el proceso de asimilación por el canon y la academia que determinan los actos donde fueron leídos.

\section{Testamento literario: pasado y presente de un subgénero tradicional}

Un testamento es una declaración personal de las últimas voluntades sobre los bienes u otros asuntos vitales. Por extensión, el término se emplea también para referirse al documento jurídico-administrativo donde se recoge esta declaración. El diccionario de la RAE recoge, además, una tercera acepción literaria: “obra en que un autor, en el último período de su actividad, deja expresados los puntos de vista fundamentales de su pensamiento o las principales características de su arte, en forma que él o la posteridad consideran definitiva”. Pero esta acepción está sujeta a diferentes usos entre los que destacan dos grandes tendencias: por una parte, la expresión "testamento literario" ha sido empleada frecuentemente por la prosa periodística para referirse a la obra última o póstuma de un escritor; por otra parte,

${ }^{6}$ Iván Carrasco se refirió a los Discursos de sobremesa como una "especie de macrotexto" ("Discursos de" 6). Se entiende por macrotexto una unidad textual superior al texto, de dimensiones inconclusas o indeterminadas. En este sentido, parece coherente referirse a estos discursos en estos términos dado que constituyen unidades independientes pero cuyo sentido completo está ligado al de la serie que, por otra parte, posee unas dimensiones que fueron creciendo progresivamente a base de reescrituras y "borradores", y superan a la nómina fijada por la publicación de 2006. 
la crítica literaria ha identificado un subgénero de literatura paródica cuyos orígenes se remontan a la Antigüedad.

Sobre la primera tendencia, un simple barrido en un buscador de internet nos aporta numerosos ejemplos que demuestran el empleo arbitrario que hace de este término la retórica periodística:

- "El testamento literario de Tom Wolfe que cuestiona a Charles Darwin"": a propósito de la obra The kingdom of speech (2016), ensayo aparecido solo dos años antes de la muerte de su autor;

- "El testamento literario de Cela": sobre la publicación de un libro inédito, Cuaderno del Espinar (2002) donde se recopilaban 13 ilustraciones acompañadas de textos que el premio Nobel presuntamente realizó durante los cuatro años que precedieron a su muerte;

- "Aparece el testamento literario de Carlos Fuentes": referido a la novela Aquiles o El guerrillero y el asesino (2016).

Estos tres ejemplos atribuyen al término un uso figurado de la palabra "testamento" y su motivación nada tiene que ver con unos rasgos textuales. Se trata más bien de una metonimia lexicalizada. A través de ella se identifica la última obra de un autor con sus últimas palabras y voluntades, de ahí que se hable de "testamento literario". Dado que no existe una motivación estrictamente textual puede suceder que dos obras de un mismo autor sean calificadas como su

\footnotetext{
${ }^{7}$ Gino Rivera. "El testamento literario de Tom Wolfe que cuestiona a Charles Darwin". Diario ABC. 11 sep 2018. https://www.abc.es/cultura/libros/abci-testamento-literario-wolfe-cuestiona-charlesdarwin-201809110216 noticia.html.

8 "El testamento literario de Cela". Diario de León.es. 21 jul 2002. https://www.diariodeleon.es/noticias/cultura/testamento-literario-cela_32490.html.

9 Jesús Alejo Santiago. "Aparece el testamento literario de Carlos Fuentes". Milenio, 3 jun 2016, https://www.milenio.com/cultura/aparece-el-testamento-literario-de-carlos-fuentes. El titular se hace eco de las palabras del editor de la obra, Ricardo Cayuela, quien afirmó a propósito de esta publicación: "Es el testamento literario de Carlos Fuentes, el gran narrador mexicano del siglo XX"
} 
testamento literario. Así sucede con la novela Federico en su balcón (2012) de Carlos Fuentes, a la que Sergio Ramírez atribuía el papel de testamento literario del autor cuatro años antes de la edición póstuma de Aquiles o El guerrillero y el asesino. A diferencia del uso que de esta expresión hiciera su editor, el escritor nicaragüense sí contemplaba unas motivaciones textuales específicas. Ramírez afirmaba: “...no sólo porque es el último de sus libros, que se publicará en breve póstumamente, sino porque la novela nos deja una lección definitiva para aprender lo que él fue como escritor, y lo que como escritor seguirá siendo en el futuro". De sus palabras se extrae que, para Sergio Ramírez, la condición de testamento literario implica no solo una obra postrera sino también un contenido donde se condense una imagen definitiva del autor.

Teniendo en cuenta, por tanto, la tercera acepción recogida en el DRAE y la descripción de Sergio Ramírez, se acogerían a la categoría testamento literario tanto obras postreras o póstumas, como textos de carácter biográfico o aquellos producidos en el ocaso de una trayectoria literaria con una voluntad aglutinante o de síntesis. Entre los textos de carácter biográfico se ubican las citadas colecciones de memorias de Rafael Alberti, Carlos Barral o Pablo Neruda. La redacción de unas memorias suele reservarse a un período avanzado en la vida del escritor o cuando este vislumbra una muerte próxima. Rafael Alberti (1902-99) trabajó en La arboleda perdida (1978-88) rondando la edad de 80 años; Carlos Barral (1928-89) dedicó los últimos veinticinco años de su vida a la redacción de sus memorias ${ }^{10} \mathrm{y}$ Confieso que he vivido (1974) apareció tan solo un año después del fallecimiento de Pablo Neruda (1904-73). Entre los textos postreros o póstumos, exentos de un contenido biográfico explícito, cabrían obras producidas al final de la trayectoria literaria de un escritor y terminadas bajo la amenaza de una muerte que se percibe como inminente. Un ejemplo de ello sería el poemario Diario de muerte del chileno Enrique Lihn (1929-88) cuyos textos fueron redactados por el autor "sitiado por la

\footnotetext{
${ }^{10}$ Estos textos se publicaron por entregas, pero fueron reunidos finalmente en un solo volumen titulado Memorias (Península, 2001).
} 
enfermedad"11, tras ser diagnosticado de un cáncer que acabaría con su vida a los 59 años. En esta obra, de hecho, el contenido memorialístico cede espacio a un tono confesional y reflexivo sobre el tema de la muerte más próximo al epitafio: "La muerte es un éxito de público / Basta con doce personas / No quiero a nadie más en la platea" (68). En similares circunstancias, la novela 2666 de Roberto Bolaño (1953-2003), puede ser vista como el testamento literario que el escritor chileno legó no solo a sus lectores sino también a sus hijos. Aparecida un año después del fallecimiento de su autor, en 2004, el chileno la habría terminado presuntamente tras ser diagnosticado de una enfermedad terminal, clausurando una obra monumental donde reaparecen situaciones, técnicas narrativas y hasta personajes que habían transitado anteriormente su obra. Como indicaba Ignacio Echevarría, el propio narrador de la obra sería el Arturo Belano de Los detectives salvajes (1998), heterónimo o alter ego del escritor ${ }^{12}$. La obra cumpliría, además, su función de testamento si se contempla el propósito materialista de su autor, quien había barajado publicar el libro en cinco volúmenes independientes para reportar el máximo beneficio a sus herederos ${ }^{13}$.

En los ejemplos reseñados, la categoría testamento literario se revela antes como lugar común recurrente en la crítica periodística que como un género o tipología textual específica. Sin embargo, indagando en el pasado se puede comprobar como la noción del testamento literario ha rondado distintos géneros revelando la existencia de una tradición específica. En ella pueden distinguirse obras de ficción de otras de carácter biográfico.

Entre las primeras, Rubio Árquez se refiere el célebre testamento de Don Quijote al final del segundo libro como paradigma de esta tradición (241). En el capítulo LXXIV del segundo libro, el personaje cervantino hace memoria y declara ante una audiencia presente (Sancho, el bachiller Sansón Carrasco, el cura, el barbero, un escribano) sus últimas voluntades y pensamientos. El carácter

\footnotetext{
${ }^{11}$ Para una interpretación de esta escritura límite, véase Espinoza Navarrete.

12 En "Nota a la primera edición" (Bolaño 1125).

13 Finalmente, la obra fue publicada en un solo volumen por decisión de los editores y en conformidad con la familia del escritor.
} 
declarativo de este pasaje coincide con el de buena parte de la novela picaresca, desde el Lazarillo de Tormes (1554) hasta La familia de Pascual Duarte (1942) de Camilo José Cela. El Lazarillo es, de hecho, el testimonio de un sujeto que hace memoria de unos hechos pasados con el propósito de justificar la estabilidad alcanzada. A este paradigma, la obra de Camilo José Cela incorpora el horizonte funerario -testamentario, por tanto- de quien afronta una inminente condena a muerte por la cual se siente obligado a confesar sus crímenes. En los textos referidos la escritura se revela como un ejercicio catártico a través del cual el narrador aviva los fantasmas del pasado con el objeto de poner orden y quedar en paz con su conciencia. "Yo, señor, no soy malo, aunque no me faltarían motivos para serlo" (Cela 37) es la fórmula de justificación con la que arranca la declaración de Pascual Duarte. Esta voluntad reparadora es comparable a la que motiva a Alonso Quijano a resarcirse ante su audiencia por su decisión de hacerse caballero andante: "Yo fui loco y ya soy cuerdo: fui don Quijote de la Mancha y soy agora, como he dicho, Alonso Quijano el Bueno" (Cervantes 575-576). Para el personaje cervantino, morir en paz significa también reconciliarse con su propia identidad.

A medio camino entre ficción y biografismo se sitúan las memorias de Gumersindo de Azcárate (1840-1917), escritor, político y jurista español. Este autor compuso una obra titulada Minuta de un testamento (1876) donde el carácter declarativo de la escritura testamentaria es utilizado como pretexto para la creación de una autobiografía ficticia en la que el autor finge ser un médico que escribe un testamento para su familia. La obra fue terminada en 1875 cuando su autor apenas contaba treinta y cinco años, por lo que el género le sirve únicamente de coartada para discutir los problemas de la España de la época.

Muy próximo al texto de Azcárate, aunque de clara intención biográfica destaca una obra titulada explícitamente Testamento literario (1929). Su autor, el novelista Armando Palacio Valdés (1583-1938), compañero generacional de Leopoldo "Alas" Clarín, firmó una colección de memorias publicada a la edad de 76 años y redactada con la plena conciencia de su condición testamentaria: 
Antes de cerrar los ojos para siempre he querido dejar reunido en el presente volumen cuanto he dicho acerca de mi arte y de aquellos que lo cultivan. Al revés de lo que acaece con la mayoría de los escritores, la edad de la observación y de la reflexión ha precedido en mí a la de la creación [...] A más de los principios estéticos que han guiado mi pluma dejo en estas páginas señalados otros más altos que han guiado mi vida $[\ldots]$ lo ofrezco al público con el título de Testamento literario, no es otra cosa que una larga y humilde confesión general del entendimiento. (Azcárate 1112)

Estas palabras del "Prólogo" preceden a las 278 páginas a través de las cuales el escritor asturiano ensartará recuerdos, personajes de su pasado, anécdotas y reflexiones en torno a la creación literaria, el arte o la filosofía sin constreñirse a un orden cronológico, sino dejando que la memoria establezca el orden y las conexiones entre sus recuerdos. En el tramo final, titulado "Últimas confesiones" (263-278), la omnipresencia de la muerte se evidencia como estímulo de esta escritura: "Heme aquí llegado al término del viaje" (265). Después de esta afirmación, el autor afronta el trance perfilando la imagen personal que quisiera legar a la posteridad: "Este estado de equilibrio moral y material sin duda se ha reflejado en mis libros, por lo cual se me ha expedido el título de optimista. ¡No!, no soy optimista" (265). Para ello confiesa viejas faltas o desvaríos de juventud: "Recuerdo el cómico desdén que sentíamos mis dos camaradas, Leopoldo Alas (Clarín), Tomás Tuero y yo por los caballeros más respetables de la población. Todos nos parecían ridículos e ignorantes: los únicos seres exquisitos éramos nosotros" (268); expone abiertamente sus filias literarias: "Los dos escritores que más han influido, no sólo sobre mi inteligencia, sino también sobre mi vida han sido Montaigne y Goethe. Aunque no por el ingenio, soy pariente suyo por el temperamento: la misma aversión a la exageración y a la violencia que ellos han sentido, la he sentido yo" (268-9) y -inmerso en la melancolía- reconoce con escepticismo el fracaso de una utopía personal: "yo vislumbré entre nubes de oro y 
grana la promesa de una nueva aurora. Después ¡ay!, caí de nuevo en las tinieblas” (278).

En la obra de Armando Palacio Valdés el contenido autobiográfico se refuerza con la intención testamentaria que deriva del empleo de la memoria como materia narrativa a través de la cual pergeñar la declaración de una voluntad personal y la construcción de la imagen propia para la posteridad. En este sentido, su función simbólica literaria coincide con la función patrimonial del testamento jurídico: hacer partícipes a los herederos de sus últimas voluntades.

Esta asociación entre el patrimonio personal y la experiencia vital constituyó el argumento central de un subgénero literario de carácter paródico cuyos primeros testimonios se remontan al ocaso de la literatura latina y se prolongan hasta el siglo XVII, pasando por los cancioneros medievales e, inclusive, llegando hasta América (García de Diego 609). Las primeras manifestaciones están datadas en la literatura romana de los siglos IV y V d. C. y constituyen un subgénero de poesía satírico-humorística muy fértil, los denominados testamentos de animales. Pilar García de Diego vincula antropológicamente esta práctica con los sacrificios ${ }^{14}$ y con el Carnaval, simultáneamente. Con el sacrificio, porque el texto se supone la respuesta a una ceremonia la cual, a su vez, determina su forma (610). Con el Carnaval, por su carácter humorístico como "medio de convertir el llanto en risa" (603). Hacia el siglo XIII, el género reaparece en las literaturas europeas en dos variantes principales: testamentos serios con carácter moral y aleccionador, y testamentos satíricos con pretensiones humorísticas que se ajustan al modelo carnavalesco original ${ }^{15}$. En la poesía cancioneril reaparecieron los testamentos literarios alternando entre expresiones sentimentales - testamentos de amores- $\mathrm{y}$

${ }^{14}$ Para justificar su hipótesis, Pilar García de Diego recuerda la etimología latina del término 'sacrificio' (<facere sacrum) y su vinculación con el testamento como parte de un ritual consistente en entregar a la víctima a los dioses, ya sea como homenaje por sus virtudes o como expiación de sus culpas (610).

${ }^{15}$ Según Rubio Árquez, el modelo original habría sido el Testament maistre Jehan de Meun redactado a finales del siglo XIII. Este documento -añade- está dividido en tres partes claramente diferenciadas. La primera y la última serían el antecedente de los testamentos de personajes reales por su intención moral, didáctica y doctrinal. La segunda parte habría inspirado los testamentos de personajes ficticios diferenciados por su intención eminentemente satírica (Rubio Árquez 244245). 
satíricas (Chas Aguión 57). Según Rubio Árquez, el género se actualizó en los testamentos poéticos burlescos redactados entre los siglos XVI y XVII, prolongación de la variante cancioneril. Esta última versión del género se caracterizó por: ser un género de literatura popular, ligado a la publicación de pliegos sueltos; poseer una retórica definida por un modelo extraliterario, esto es, el testamento jurídico; una presencia explícita del testador como agente del discurso; un juego retórico basado en hacer desfilar con sentido burlesco a personajes relacionados con el autor del testamento (médicos, escribanos, familiares...); el carácter secundario del texto que es interdependiente de obras mayor importancia del autor (251).

Con matices, se trata de características comunes a otras manifestaciones del género. En su análisis de los trece testamentos hallados en la poesía cancioneril, Chus Aguión se refiere al carácter interdiscursivo de este género de composiciones: "La carencia de una preceptiva teórica quedó suplida, por tanto, por la imitatio de un modelo compositivo en principio paraliterario, que paulatinamente irán adaptando a sus propios intereses los poetas de cancionero" (66). Este autor observa, además, la existencia de una estructura convencional en la que la inminencia de la muerte constituye el pretexto argumental del exordio:

Pois me vejo a norte chegado

mis boos amigos, en esta sazón, por tanto eu fazo, ¡si Deus me perdón!

o meu testamento assi ordenado ${ }^{16}$

En este fragmento, el uso explícito de la palabra 'testamento' para calificar el escrito revela la conciencia del género que se maneja. Por otra parte, la correspondencia entre el testador y el agente de discurso incorpora al género una naturaleza performativa-simulada, claro está- que se materializa en varios recursos

16 Texto de Gonzalo Rodríguez, Arcediano de Toro en Cancionero de Juan Alfonso de Baena. Madrid: Visor, 1993, p. 556 (Ctd. en Chas Aguión 69-70). 
textuales: la mención burlesca a la edad del testador y la invocación en forma de apóstrofe a una audiencia presente ("oyentes") que, en el plano legal, figuraría como testamentario;

Y porque nunca son malos

mis dádivas y presentes, sepan todos los oyentes

que las plumas de mis alas $[\ldots]^{17}$

Esta condición se acentúa con la firma y la datación del texto. Estas tres marcas se pueden ver claramente reflejadas en un testamento satírico, presuntamente del siglo XVII, donde el "escribano" toma la palabra al final de la declaración:

El testamento extremado

que, aquí, señores, bien veis,

a los quince fue acabado

de setiembre señalado

año de noventa y seis

Testigos: Martín Lovato

y Fernando Calderero,

y Martín Páez Tripero,

con Gonzalo Garabato,

y Domingo Vinadero,
Juan Talego y Juan Tropel,

Miguel Turca Mantequero

con Benito Molcochero

Luis Pablo de Daymiel

y Rodrigo Morullero

Yo, Juan Pérez, escribano

con bastante autoridad, este testamento llano

lo firmo aquí de mi mano

y doy fe como es verdad ${ }^{18}$

El texto representa un ejercicio retórico mediante el cual se vincula paródicamente el documento con su correlato no literario al tiempo que pone de

17 “Testamento de M. Grunnio Corocota Porcelo" (Ctd. en García de Diego 625)

18 “Testamento del gallo” (Ctd. en García de Diego, 626). 
manifiesto su carácter lúdico y carnavalesco. La gracia de estos versos se sustenta en la desublimación de una experiencia vital percibida como traumática, transformando la risa en llanto, como presuponía García de Diego: "La gracia de este testamento [Testamento de M Grunnio Corocota Porcelo], que regocijaba a la juventud romana, consiste en tomar a broma un sacrificio sagrado, en hacer de él una parodia" (622).

Así pues, a propósito de las diferentes variantes observadas como ejemplos de testamentos literarios, se pueden bosquejar como rasgos propios de esta práctica literaria:

- El carácter declarativo-performativo del hablante, explicitado en referencias a un auditorio presente y a una situación enunciativa concreta (fechas, lugares, nombres de testigos).

- El empleo de la memoria como fundamento temático del género y su plasmación fragmentaria en el relato. En el ejercicio de la memoria alternan recuerdos, personas y anécdotas que son traídas al presente con el objeto de ajustar cuentas con el pasado, extraer enseñanzas o, sencillamente, bromear con la distancia irónica que proporciona el paso del tiempo. Al tratarse de un relato trazado a través de memorias y no con el rigor cronológico del relato biográfico, tiende a la fragmentación y los saltos temporales.

- La intención de expresar unas últimas voluntades y, con ello, fijar una imagen propia administrada por el testador.

- La dependencia interdiscursiva con un modelo extraliterario, el testamento jurídico-administrativo.

- El carácter secundario de los textos con respecto a obras anteriores.

- El carácter ritual ligado a una ceremonia de despedida (sacrificio) y carnavalesco, como acicate contra la seriedad, la solemnidad o el dramatismo asociado a este tipo de eventos.

Estas características formarán parte de un género testamentario contemplado por Belén Gache (2006) como una corriente de escritura experimental contemporánea. Esta autora mexicana reconocía la existencia de un común 
denominador entre las nuevas direcciones de la escritura experimental ("nomadismos") en el cambio hacia un paradigma abierto materializado en el tránsito derridiano de una concepción cerrada (libro/significado) a un planteamiento abierto (texto-hipertexto/significante) o hipertextual. Bajo esta premisa, Gache distingue al género testamentario por ser aquel que confiere al texto una dimensión trágica, en tanto señala la inminencia de la muerte del enunciador (244). Siguiendo la tradición anteriormente citada, Gache llama la atención sobre la subordinación intertextual del género a un modelo extraliterario, el Curriculum Vitae, basándose en tres rasgos discursivos comunes: a) invoca una responsabilidad jurídica del enunciador (performatividad), b) hace coincidir el presente de la enunciación con el pasado de la memoria (memorialismo) y c) se presenta como una textualidad discontinua (fragmentarismo) (246-247).

En definitiva, cabe considerar la existencia de un subgénero de escritura emparentado con la tradición satírica del testamento literario. Además de la condición extratextual atribuida a obras postreras o póstumas, su práctica estará subordinada a la existencia de una producción previa y tendrá por objetivo la construcción personal de una imagen de autor donde se condensen rasgos, motivos e ideas recurrentes y reconocibles por el lector familiarizado. Estos textos funcionarán semánticamente en la borrosa línea que separa el sujeto civil de la imagen pública del autor. En este sentido se distinguen por su performatividad pero también por un empleo fragmentario y, en ocasiones, arbitrario de la memoria que podrá manifestar así sus deficiencias pero también una caprichosa selección de los acontecimientos pasados. Este género de textos reproduce dramáticamente el ritual de la despedida y localizan en el presente de la enunciación la narración del pasado.

\section{La puesta en escena del testamento literario}

En el año 1988, el triunfo del "no" en el Plebiscito puso fin a más de una década de dictadura y violaciones de los derechos humanos. El fin de la dictadura y la recuperación de la libertad política significaron el regreso de muchos intelectuales exiliados y el fin de la censura. Durante aquellos años, Nicanor Parra 
había permanecido en el país y su actividad poética e intelectual -aunque no se interrumpió- se vio obligada a sortear la censura, unas veces en forma de Chistes parra desorientar a la policía poesía (1983) y otras, enfundado bajo la máscara de un extravagante predicador, el Cristo de Elqui. Permanecer en el país le convirtió para algunos escritores del exilio en sospechoso de aquiescencia con la dictadura, lo que no le eximió de roces con el poder como demuestra el capítulo del montaje teatral Hojas de Parra. Salto mortal en un acto realizado en 1977 y frustrado por la presión de las autoridades municipales. Por aquellos años su actividad se mantuvo en un plano discreto entre publicaciones de carácter artesanal y tirada limitada, y volúmenes antológicos como Poesía política (1983) u Hojas de Parra (1985). Simultáneamente, su figura literaria creció tanto dentro como fuera del país. Fruto de esta popularidad, el poeta llegaría a ser postulado al premio Nobel hasta en cuatro ocasiones (1995, 1997, 2001 y 2012) y, desde la década de 1990, los premios y homenajes a su trayectoria literaria se fueron haciendo cada vez más frecuentes. El detonante de este proceso de "canonización" de la poética de Parra tuvo su pico en la invitación a la Feria del Libro de Guadalajara en 1991 donde recibió el Premio Juan Rulfo en su primera edición, para el cual competía con candidatos de la talla de Ernesto Cardenal. Como admitió el poeta en su discurso de agradecimiento, el premio significaba un reconocimiento a la poesía chilena después de quince años de dictadura, pero también la consagración de la antipoesía en el panorama literario latinoamericano: "Sé perfectamente/ Que éste no es un premio para mí/ Sino un homenaje a la poesía chilena” (571). Este reconocimiento institucional entraba en contradicción con el carácter transgresor inherente al proyecto de la antipoesía, que en su ética particular rehúye el canon como construcción cerrada, estática: "Antología/ Por orden del Papa" (Parra Obras completas, vol. I, 439). Por esta razón, el reconocimiento institucional le atribuía una "autoridad" literaria que, indirectamente, mermaba el potencial antiartístico de su poesía. En Guadalajara proclama: 
Con este premio paso a la categoría

De caballero de la triste figura:

Donde me siente yo

Está la cabecera de la mesa caramba! (587)

Ante la diatriba de ver su poesía absorbida por el aparato de la institución académica - un "sacrificio" para una poética que había venido a "romper con todo"el poeta se inventó una fórmula personal y de clara raíz antipoética para dar respuesta a las distinciones: los discursos de sobremesa. A sabiendas de que este género de ceremonias contempla una respuesta del homenajeado, Nicanor Parra programó teatralmente sus intervenciones, manipulando los códigos del protocolo y poniéndolos al servicio de un "espectáculo" que poco a poco se convertiría en el particular canto de cisne de la antipoesía. En sus discursos hilvanó antipoemas, artefactos, recuerdos, anécdotas, lecturas, declaraciones estéticas y políticas que, en conjunto, pergeñan una síntesis de su pensamiento y anuncian el agotamiento de su imagen pública. Así lo notaba en el discurso pronunciado en 1996:

Me propongo pasar a la reserva

Como el tra(i)ductor de Hamlet

Al mapudungun

No como poeta ni como antipoeta

Pasaron esos tiempos calamitosos (744)

En el discurso de sobremesa, el poeta hace coincidir una larga tradición (el simposio platónico) con una tradición autóctona y popular (el "discurso chileno o huaso"19) y con un modelo protocolario, preestablecido en nuestra tradición

19 En Nicanor Parra tiene la palabra, Jaime Quezada pone en boca de otros autores algunas descripciones del género que lo identifican con una forma de chilenidad. Mario Rodríguez explica: 
sociocultural. En este sentido, Iván Carrasco habla de una función social y literaria simultáneas ("Discursos de" 8). Para él, la construcción estratificada del discurso de sobremesa, variante de la antipoesía, coincide con el paradigma de texto polivalente propuesto por Tsvetan Todorov, el cual distinguía aquel del texto monovalente en su capacidad para evocar discursos anteriores: "Podríamos denominar monovalente al discurso (que también sólo cabe pensar como límite) que no evocase de ningún modo 'maneras de hablar' anteriores; y polivalente, a aquel que sí lo hace de manera más o menos explícita." (68). Desde esta óptica, Carrasco propone leer la antipoesía como textos donde se pueden reconocer dos o más entidades: una instancia poética o texto transtextual que actúa sobre una instancia antipoetizada mediante la homologación falsa o aparente, la inversión o la deformación satírica del modelo (Para leer 117). En los discursos de sobremesa, la "instancia antipoetizada" se revela directamente en el título y apunta hacia esa variante de oratoria pública que Juan Gabriel Araya y Mario Rodríguez identifican en una tradición local. Además, en la medida en que fueron concebidos para insertarse dentro del protocolo de una ceremonia pública constituyen un discurso social, como propone Carrasco. De acuerdo con ambas lecturas, existen también razones para leer el conjunto de los discursos como un testamento literario cuya especificidad radica en su proyección oral y, por tanto, pública y performativa.

En primer lugar, cabría considerar la localización de estas piezas en la última etapa de producción literaria del autor. Constituyen, vistas en conjunto, la última serie reconocible semejante a otras anteriores como los antipoemas, los artefactos o los monólogos dramáticos protagonizados por el Cristo de Elqui. En segundo lugar, cada uno de estos discursos se presenta como una declaración pública programada y ejecutada dentro de unas coordenadas institucionales que se

"es un discurso plenamente chileno. Nicanor Parra, desde este punto de vista, es el gran poeta chileno, el gran poeta nacional. Y es un discurso profundamente chileno porque está unido a una forma de nacionalidad [...] Cuando están todos medio achispados y le ofrecen la palabra a alguien. Y ese señor se pone d pie y habla. Hablar y sacarse los balazos porque sabe que los comensales que están ahí- pueden interrumpirlo en cualquier momento" (109). Por su parte, Juan Gabriel Araya afirma que "Un Discurso de sobremesa, en la tradición chilena recogida por Parra en Chillán, es un discurso que un sujeto realiza después de una comida bien regada para agradecerle a alguien el agasajo que le brindan, el homenaje u obsequio que le hacen [...]” (131). 
corresponde con la condición de "poeta laureado"20. Consciente de las implicaciones sociales y políticas que rodean a este género de actos, el homenajeado aprovecha el foco de atención ${ }^{21}$ para expresar sus últimas voluntades ante una audiencia que -como sospecha irónicamente- le rinde tributo debido a su avanzada edad: "Seguramente lo que + pesó/ Fueron las razones de orden humanitario" (1116). Confirman ambas hipótesis las propias declaraciones del autor quien, por aquellos años, apuntaba a los discursos de sobremesa como un proyecto último y definitivo donde volcar toda su experiencia literaria:

Ana $\mathrm{M}^{\mathrm{a}}$ Larraín: ¿En qué etapa
se encuentra ahora su
quehacer?
Nicanor Parra: "Aparte de mis
trabajos prácticos, parece que
todo converge hacia los
"discursos de sobremesa”, un
tipo de textos que parecen muy
tontos, pero ¡cuidado! Hay
planteamientos de profundidad
ahí" (Cárdenas 143)

Ana Ma Larraín: ¿En qué etapa se encuentra ahora su quehacer?

Nicanor Parra: "Aparte de mis todo converge hacia los "discursos de sobremesa", un tipo de textos que parecen muy ahí" (Cárdenas 143)
(1)

\author{
Juan A. Piña: ¿Qué otros \\ textos, además, \\ estás escribiendo ahora? \\ Nicanor Parra: Unos Discursos \\ de sobremesa. Creo que aquí \\ desembocan todos los \\ experimentos anteriores. (Parra \\ "La antipoesía" 45)
}

Por otra parte, la coartada dramática del discurso de agradecimiento recuerda al uso político que Gumersindo de Azcárate hace del testamento y la sensación de urgencia coincide con la angustia por la inminencia de la muerte que

\footnotetext{
${ }^{20}$ El poeta laureado es una figura prácticamente inexistente en el ámbito hispánico pero que ha conservado el mundo anglosajón, donde se habla de "poet laureate". Se trata de un artista cuyas cualidades literarias le hacen acreedor de un puesto honorífico concedido por la autoridad competente en calidad del cual figura en las ceremonias oficiales como una suerte de embajador de la poesía nacional. Por citar un ejemplo, desde mayo de 2019 Simon Armitage detenta esta distinción en el Reino Unido.

21 En un análisis pionero, Mario Rodríguez observaba como rasgo distintivo del discurso de Guadalajara (1991) con respecto a un discurso anterior en honor de Pablo Neruda (1962) el tránsito de una posición simbólica "marginal" (el "francotirador" de 1962) a la centralidad de la mesa (el "poeta reservista" de 1991): "Los discursos de sobremesa sintetizan el comienzo y el fin de una guerrilla literaria de 30 años, emblematizada en la figura del desplazamiento del sujeto triunfante desde el lugar lateral en la mesa de homenaje hasta la cabecera o puesto central de la misma, y en la transformación de dicho sujeto de francotirador a reservista. El desplazamiento y la transformación implican dos cosas: el desalojo del poeta padre y la consecución del objetivo deseado: ser la voz de la tribu." (8).
} 
estimula el Diario de muerte de Enrique Lihn. Pero, además, en los discursos de sobremesa pueden reconocerse rasgos textuales que conectan estas piezas con ese género de escritura que glosamos en el apartado anterior: el testamento literario.

Sobre este particular, cabe aclarar que estas obras no parodian directamente el documento legal como sucedía en los testamentos literarios analizados en el apartado anterior. Coinciden con dichos textos en su estilo declarativo y performativo, el memorialismo y la ejecución dramática del género. En los discursos de Nicanor Parra, la memoria y los recuerdos en forma de anécdotas constituyen el tema central. Buena parte de Also Sprach Altazor (1993) es una evocación de la "guerrilla literaria" 22 que le sirve para actualizarla y tomar posición dentro de ella ${ }^{23}$ (Gumucio 254). Aunque no vengo preparrado (1997), el discurso pronunciado en Valdivia rememora, junto a la figura de Luis Oyarzún que da nombre al premio, pasajes de la bohemia santiaguina por donde desfilan otras personalidades literarias como Enrique Lafourcade, Enrique Lihn o Alejandro Jodorowsky, entre otros.

Así pues, para una lectura de los discursos de sobremesa en clave de testamento literario, cabe considerar tanto aspectos no textuales como otros que hacen referencia a una textualidad específica, esto es, el género testamentario.

Entre los aspectos no textuales, deben tenerse en cuenta tanto la localización cronológica de estas piezas como su adscripción a una ceremonia social. En lo que respecta a la localización, aunque el último de los discursos incluidos en este corpus se pronunció en 2001 -diecisiete años antes de la muerte del poeta-, debe tenerse en cuenta que, por aquel entonces, Nicanor Parra ya era un poeta octogenario. El poeta había comenzado a anunciar públicamente su deseo de retirada y vislumbraba, en

\footnotetext{
${ }^{22}$ Para este concepto que Parra parodia con el vocablo "Poetomaquia", véase Faride Zerán. En su obra, la autora hace un relato de las disputas y desencuentros entre los tres grandes poetas de la Vanguardia chilena: Vicente Huidobro, Pablo de Rokha y Pablo Neruda. El poeta pudo claramente inspirarse en esta obra al redactar su discurso, pues había aparecido justo el año anterior.

${ }^{23}$ Mario Rodríguez (1997) y Rafael Gumucio (2018) coinciden en reconocer al hablante de estos discursos como un participante de última hora en la "guerrilla literaria". Según Rodríguez, "los discursos de sobremesa sintetizan el comienzo y el fin de una guerrilla literaria de 30 años" (8). y Rafael Gumucio, por otra parte, entiende que en los discursos Parra aprovecha la ocasión para lanzarse el también en la Poetomaquia" (254).
} 
poemas y entrevistas, la omnipresencia de la muerte. La enfermedad y la vejez son, de hecho, temas recurrentes sobre los que se pronuncia:

\section{W.C PrOblEM}

To $\mathrm{P}$ or not to $\mathrm{P}$

That is the question

Agrupación de Enfermos de la Próstata (616)

\section{NO ME EXPLICO SEÑOR RECTOR}

Las razones que pudo tener el Jurado

[...]

\section{HAY UNA SOLA EXPLICACIÓN POSIBLE}

El estado precario de salud

En que se debate el anciano decrépìto (1113)

La percepción de una muerte cercana le conduce a representarse a sí mismo en los discursos como el objeto de un "sacrificio", actualizado e irónicamente identificado con la ceremonia de homenaje:

Creo tener bien en claro

Lo que esta ceremonia significa

Premio a la longevidad

Dentro de poco cumpliré los 100 (758)

\section{HAY UN METODO INFALIBLE}

Para hacer trabajar gratis a un viejo

Por arruinado o achacoso que esté: 
Otorgándole un premio literario (810)

Vivo no me pondrán en el ataúd:

Al cementerio x mis propios pies (1117)

Integrados dentro de una ceremonia específica, los discursos de sobremesa aportan el testimonio de una declaración pública. En la traducción al inglés, titulada After-dinners declarations, el traductor Dave Oliphant justificaba la elección del vocablo "declarations" en lugar de "discourses" o "speeches" como una manera de sortear tanto la formalidad asociada al primer término como el desarreglo asociado al segundo. Estimaba que "declarations" se aproxima más a la intención del autor de intervenir sobre unas condiciones de realidad: "His speeches are indeed filled with «declarations» (of independence) on a wide range of pressing issues..." (i y ii). Una declaración es un tipo de texto que se realiza en presencia de un auditorio concreto y está asociado a unas condiciones espacio-temporales de enunciación. Ambos parámetros son determinantes en relación con el significado y los efectos perlocutivos del enunciado. Cada uno de estos textos, en calidad de discurso público, se inscribe dentro de unas coordenadas de enunciación específicas. A diferencia de un texto literario tradicional donde domina la función poética y la voluntad de funcionar en el espacio abstracto de la expresión literaria, estas alocuciones fueron dispuestas para inscribirse en un espacio y un tiempo determinados. Algunas tienen como título o subtítulo su lugar de ejecución: "Mai Mai Peñi" se subtitula "Discurso de Guadalajara", mientras que "Discurso del Bío Bío" o "Discurso de Valdivia"24 explicitan desde el título el acto para el que fueron creados. En algunos discursos, la fecha ocupa un lugar específico como paratexto: "Guadalajara/ A 23 de noviembre de 1991" (605), "En Santiago de Chile/ A 23 de

\footnotetext{
${ }^{24}$ A esta lista podría incluirse otro discurso pronunciado en estas fechas que permanece inédito. Se trata de "Discurso de la Alameda" (1994), un discurso pronunciado en el Centro Cultural Alameda durante la celebración del 80 aniversario del poeta y al que algunos autores se han referido como "Parralabras". La única muestra conocida hasta la fecha es una transcripción incompleta aparecida en el diario La Nación, 1 sep 1994, p. 53.
} 
abril de 1993" (635); o se integra en el cuerpo del texto: "QUÉ DIREMOS DE ÉL/ Hoy 10 de enero de 1993”25 (640). Si la localización de la enunciación inscribe el texto en un contexto específico, las interpelaciones al auditorio y a personalidades concretas subrayan el carácter de documento público de las piezas. En 1996, por ejemplo, el poeta cita directamente a personas presentes en el acto transformando la expresión de agradecimiento, en un registro de los "testamentarios" de su declaración pública:

\section{GRACIAS TITO TRIVIÑOS}

Alguna vez me vengaré de ti

$[\ldots]$

Gracias Ivette

Gracias María Nieves

Hadas madrinas sin cuyos artilugios

El machitún no creo que hubiera sido posible

Tiempo que Uds. vienen estudiando

Los pormenores de esta poesía

Con una paciencia digna de mejor causa

Alguna vez se arrepentirán (758)

\footnotetext{
${ }^{25}$ En este caso, la fecha contradice la que aparece en el pie del texto: "Las Cruces, 3 de septiembre de 1993". Como se sabe, una de las casas del poeta y donde pasó buena parte de sus últimos años se encontraba en el balneario de Las Cruces, entre Cartagena e Isla Negra. Esta datación debe referirse a la última revisión del texto, pues el discurso habría sido preparado en origen para los actos del centenario de Vicente Huidobro en enero de 1993. No obstante, la primera noticia que se tiene de la lectura pública de este discurso es del 3 de septiembre de 1993 en la localidad de Lo Abarca (Véase diario La Época, 12 sep 1993, pp. 7 y 8). Sabemos que el discurso fue retomado por el autor, al menos, hasta en dos ocasiones, en 1995 y en 2001. Para abreviar, dejamos abierto este interrogante para ulteriores estudios.
} 
Así pues, estas obras participan performativamente de unas condiciones de realidad donde el autor $-\mathrm{o}^{\prime}$, al menos, su imagen pública (antipoeta)- coincide con el enunciador del texto en un juego dramático-teatral que, como un acto liminal, está funcionando entre dos planos: el del juego literario y el de la formalidad social. Asimismo, el declarante, al exponer públicamente su voluntad y opiniones, asume el rol de "testador" cuyas afirmaciones legitiman al tiempo que contradicen la propia ceremonia: "Terminamos nosotros con los premios/ O los premios terminan con nosotros" (1118).

Desde un punto de vista textual, el memorialismo, la condición autobiográfica, la intertextualidad y la condición secundaria (autotextualidad) de los discursos constituyen rasgos que emparentan estos textos con los testamentos literarios paródicos así como con otras manifestaciones posteriores. En conjunto, los discursos de sobremesa bosquejan unas memorias personales en las que se pueden distinguir anécdotas, personajes, ideas, opiniones y lecturas que el orador rescata fragmentariamente como recuerdos que le asolan sin un plan previo. "Hablando de peras el antipoeta puede salir perfectamente con manzanas" (Neruda y Parra 13), avanzaba una poética del género en un discurso anterior de $1962^{26}$. Así, la semblanza que en 1991 hace en torno a Pedro Páramo de Juan Rulfo aparece salpicada de citas y paráfrasis de Adorno, Rimbaud o Derrida. En 1993, su homenaje a Shakespeare le sirve de pretexto para elaborar una disquisición en torno a esa "neurosis" de la antipoesía que se debate entre la influencia anglosajona y la tradición castellana: "Ya lo dijo mi tía/ Shakespeare/ el Cervantes inglés/ Cervantes/ el Shakespeare español" (624). A través de la memoria, el poeta trae al presente recuerdos y anécdotas con diferente propósito. A veces, la intención es producir un chiste ligero (“FUMABA TANTO O MÁS QUE LA MISTRAL/ Algo que a mí me pone los pelos de punta/ Soy asmático de nacimiento/ Por eso nunca pude hablar con él [Juan Rulfo]", 565) o justificar sus posiciones estéticas ("Yo

\footnotetext{
26 "Discurso de bienvenida en Honor de Pablo Neruda" (En Neruda y Parra 9-48). En su estudio pionero sobre los discursos de sobremesa, este discurso era presentado por Mario Rodríguez (1997) como una suerte de ensayo primitivo del género.
} 
quería escribir como se habla/ En cambio él [Luis Oyarzun] se sentía muy bien/ Hablando/ Como quien está leyendo un ensayo de Heidegger", 797). Otras veces, la memoria ejerce una función catártica como sucede en su evocación del presidente Salvador Allende durante el "Discurso del Bio bio", con quien había mantenido importantes diferencias en medio del fervor revolucionario que precedió al Golpe de Estado de 197327:

\section{EXPLOSIÓN DEMOGRÁFICA DE DOCTORES}

El Dr. Lenz

Iniciador de los estudios antropológicos en este país

El Dr. Oroz

El Dr. Salas

Candidato a la Presidencia de la República

Salas Sale Solo

El Dr. Nicolai \& el Dr. Liptchuz

$[\ldots]$

\& el Dr. Salvador Allende Gossens

$\mathrm{El}+$ caro de todos los Doctores (731)

Simultáneamente, estas piezas contienen una manifestación pública de la ideología del autor que, por aquel entonces, se declaraba activista del ecologismo y defensor de los derechos humanos y de la causa mapuche. A través de los discursos, Parra se pronuncia sobre cuestiones de la actualidad más inmediata tanto fuera ("Una buena patada en el hocico/ Para el Generalísimo de moda/ Por las brutalidades que está cometiendo/ Contra la diminuta República de Chechenia", 755) como dentro de Chile ("Mucho se habla de derechos humanos/ Poco/ nada casi sobre deberes humanos/ Primer deber humano/ Respetar los derechos

\footnotetext{
${ }^{27}$ La postura independiente y, a veces, desafiante hacia el entorno cultural y político de la Unidad Popular constituyó uno de los bloques temáticos de los Artefactos de 1972. En uno de ellos se podía leer: "Donde cantan y bailan los poetas/ No te metas, Allende, no te metas".
} 
humanos", 592, 756 y1115). Son recurrentes, por otra parte, sus declaraciones en torno a la causa mapuche o la alarma ecológica que, a base de repetirlos, se convierten en eslóganes susceptibles de ser encajados en cualquiera de los discursos:

\author{
EN RESUMEN \\ en síntesis \\ en buen romance
}

Muchos los problemas

Una la solución

Economía Mapuche de Subsistencia (761)

Estas declaraciones políticas e ideológicas le sirven para moldear una imagen de autor donde contrastan el activista social con el poeta ególatra e irreverente en retirada ${ }^{28}$. Como el viejo poeta agasajado se muestra irreverente y desvergonzado, ambicioso y materialista:

Qué nota le pondrías

Al Primer Mandatario de la Nación

Aquí presente (silencio prolongado)

Un seis a siete...

En escala de 1 a 5 (619)

${ }^{28}$ En este punto existen diferentes caracterizaciones del "personaje" representado por Nicanor Parra a lo largo de estos discursos. La primera se la debemos a Mario Rodríguez quien se refiere al poeta como "reservista", entendiendo por tal una prolongación del "francotirador" del "Discurso de bienvenida en honor de Pablo Neruda" pronunciado en la Universidad de Chile en 1962 (6). Niall Binns, por su parte, lo caracteriza como un "vanidoso anciano hambriento de premios" (82). 
Agradezco los narco-dólares

Harta falta que me venían haciendo (590)

Sin embargo, en calidad de poeta activista, manifiesta una y otra vez su preocupación por cuestiones medioambientales y sociales. En general se adivina un deseo de definir su propia ideología ("Políticamente/ Cómo te defines en la actualidad/ Como un anarquista renovado", 618). Como antipoeta, sortea la contradicción entre su conciencia social y su "egolatría” literaria amparándose en el subterfugio de la vejez y la autoridad literaria que le confiere su condición de "poeta laureado": "Donde me siente yo/ Está la cabecera de la mesa caramba!, advertía en Guadalajara (587).

Además de las declaraciones de carácter político, los discursos contienen un muestrario de sus afinidades y discrepancias políticas, sus ideas estéticas y sus juicios literarios. En “Also Sprach Altazor” expresaba su admiración -contenida, eso sí- por Vicente Huidobro ("NO SOY TAN PARRANOICO/ Como para pensar/ Que Huidobro es el hoyo del queque”, 719) y se posicionaba, indirectamente, en el bando contrario a Pablo de Rokha con sutiles ataques y burlas contra el poeta. Del mismo modo, en "Happy birthday", se expresa abiertamente sobre su controvertida relación con Pablo Neruda:

Quién es Pablo Neruda para ti

Uno de los poetas + grandes del siglo XX

Cómo te relacionas con él

A Little more than kin and less than kind

Algo + que parientes lejanos 
Pero bastante menos que hermanos siameses (620)

Arte Poética

$1 \%$ de inspiración

2 de traspiración

$\&$ el resto suerte (746)

La construcción de esta imagen está marcada en líneas generales por una sensación de agotamiento que apunta en la dirección de un texto testamentario. Como antipoeta en retirada contempla obsoleta su propia fórmula literaria:

\section{PROYECTOS?}

claro que sí!

Me propongo pasar a la reserva

Como el tra(i)ductor de Hamlet

Al mapudungun

No como poeta ni como antipoeta

Pasaron esos tiempos calamitosos (744)

Lo mismo sucederá con su ideología y visión del mundo:

NO SÉ NO SÉ

Yo pertenezco a un mundo que se fue

Yo todavía creo en el ser humano

Yo todavía creo en Dios y en el Diablo

Para decirlo todo de una vez

Yo soy 
Uno de esos engendros modernistas

Que confundieron el Ser con el Ente (1117)

Si desde un punto de vista temático, el memorialismo y el biografismo relacionan estos discursos con el género testamentario, su textualidad secundaria y paródica también lo hacen. Estos discursos dependen e interactúan textualmente con producciones anteriores (autotextualidad). Deberían ser leídos como una pieza suplementaria a la producción anterior de su autor. Estos textos no se sostienen sin el horizonte de los antipoemas, los artefactos o la práctica del monólogo dramático en Sermones y prédicas del Cristo de Elqui. En ellos reaparece el sujeto escindido de la antipoesía ("Yo es Yo / Yo es Otro / Yo es nadie [...], 746), las voces anónimas de los artefactos y los chistes (“Árbol / Lo único que te pido / Es que me quites el sol”, 628) así como la voz de su personaje más reconocible, el Cristo de Elqui: “¿QUÉ PASARÁ EN EL PRÓXIMO SIGLO? / Vuestro señor Jesucristo de Elqui no + lo sabe" (806). En este sentido, buena parte de los textos que componen estos discursos son deliberadamente traídos de vuelta como jirones de textos anteriores. Esta "reescritura" elaborada a base de autocitas presupone un conocimiento de la producción anterior en la que se sustenta y que encuentra una prolongación en el marco de los discursos donde los fragmentos no solo son desplazados sino también resignificados. Apartados como "Frases Par(r)a el bronce" (592) o "Consejos teóricos \& prácticos" (745) evocan la poesía epigramática de los Artefactos, los Chistes o los Ecopoemas y la traducción del monólogo de Hamlet encabezada por el rótulo "W.C PrOblEM" implica no solo una reescritura sino también una resignificación del texto anteriormente aparecido en Hojas de Parra (1983). Más allá, el poeta crea fórmulas lexicalizadas ("Gracias señor rector", "\& last but not least", "ültima hora-urgente", “dice... debe decir...”, etc.) que reenvían al lector a textos previos, contribuyen a forjar la unidad del género y anclan este lenguaje en una práctica antipoética consistente en reproducir gestos del habla como el empleo de dichos y muletillas. Aparte de esto, la propia condición de discurso de agradecimiento inscrito en una ceremonia de homenaje a un escritor presupone la 
existencia de una obra que justifique el acto. Para "ocupar el centro de la mesa", el orador requiere que la comunidad le conceda ese espacio de autoridad arrebatado a su rival del discurso de 1962: "Donde me siente yo/ Está la cabecera de la mesa caramba!", sentenciaba en el discurso de Guadalajara.

Por último, los discursos de Nicanor Parra reproducen paródicamente una tipología textual no literaria (intertextualidad) del mismo modo que lo hacían los testamentos de animales o los testamentos poéticos burlescos. Así como estos últimos imitaban de forma burlesca un subgénero de texto administrativo, los discursos de sobremesa se apoyan en un subgénero de la oratoria contemporánea ligado al protocolo de los actos de reconocimiento: el discurso de agradecimiento ${ }^{29}$. Este modelo puede reconocerse tras las fórmulas de falsa modestia ("Señoras \& señores/ Antes de proceder a dar las gracias/ x este premio tan inmerecido", 558), para ceder la palabra ("Los oradores que me han precedido en el uso de la palabra/ Han dicho todo/ Prácticamente todo lo que se puede decir al respecto/ Qué se hace en un caso como éste/ No sé", 765) o para expresar gratitud ("QUISIERA AGRADECER/ A los organizadores de este encuentro/ La oportunidad que se me da/ A mí que soy el más sospechoso de los invitados", 609). Como veíamos anteriormente, la intertextualidad de estas obras posee diferentes estratos entre los que se advierten el simposio griego, el discurso huaso o el discurso de agradecimiento. Si se toman en consideración la ubicación de los discursos en el último tramo de la producción de su autor, el carácter autobiográfico y memorialístico donde convergen recuerdos, opiniones, lecturas y personajes relacionados con la vida del autor, la voluntad sintética y aglutinante, las autocitas y su función social como puesta en escena de una despedida, todo apunta a reconocer una textualidad adicional: el testamento literario.

\footnotetext{
${ }^{29}$ Sobre los diferentes tipos de discurso social, véase Antonio Briz (262-269).
} 


\section{Conclusiones}

Este trabajo sugiere una lectura de los Discursos de sobremesa de Nicanor Parra en clave de testamento literario. Su escritura motivada por la necesidad de cumplir con un protocolo, el momento vital en que fueron compuestos y la contradicción que acechó al poeta ante su proceso de consagración como autoridad literaria habrían estimulado al autor a hacer de ellos algo más que un mero texto formal para la ocasión. Algunos ejemplos fueron reunidos posteriormente en la publicación de 2006. La existencia de otros textos coetáneos similares y concebidos con el mismo objetivo permite replantearse esa nómina de cara a observarlos como una serie de dimensiones por determinar. Con el propósito de abrir este debate, se han incluido como objeto de análisis otros tres textos concebidos como "borradores" pero editados en el segundo volumen de las obras completas del autor. A partir del corpus señalado se ha realizado un breve recorrido histórico en torno a la cuestión del testamento literario. Dicha categoría ha sido analizada estableciendo un contraste entre el empleo retórico que le hace de ella la crítica periodística y la existencia de una tradición específica cuyas primeras manifestaciones se hallan en el período tardío de la literatura romana. Tras analizar la existencia de diversas manifestaciones a lo largo de la historia y conjeturar sobre los usos que más recientemente se han hecho de esta categoría, se ha propuesto la consideración de una serie de rasgos comunes a este tipo de escritura de naturaleza paródica, dramática y performativa en tanto se sirve del juego de la imitatio.

Una vez establecidos estos rasgos, el análisis se ha volcado en justificar la lectura de los discursos de sobremesa como un testamento literario. Como se advirtió desde el principio, no se trataba de afirmar rotundamente su adscripción a este género de escritura sino, más bien, de identificar las afinidades -quizás involuntarias- que los emparentan con él. A tal efecto y considerando los discursos una continuación en sus aspectos esenciales de la propuesta estética iniciada con la antipoesía, se ha partido de la propuesta de Iván Carrasco de una lectura de las obras como texto polivalente para indagar en los diferentes estratos textuales reconocibles en los discursos. Así pues, teniendo en cuenta las circunstancias en que fueron 
escritos, cuando el poeta rondaba los ochenta años y enfrentaba unos "laureles" que mermaban la capacidad subversiva originaria de su propuesta poética, y teniendo en cuenta también las características textuales y temáticas (empleo de la memoria, carácter secundario de los textos), se concluye que estas obras podrían haber cumplido una doble función: responder a la formalidad de los actos y, al mismo tiempo, materializar el deseo anunciado por el poeta en aquellos años de retirarse de la esfera pública. En este sentido, los discursos de sobremesa significarán, en el conjunto de la producción del autor, la puesta en escena de un testamento literario.

\section{Bibliografía}

Azcárate, Gumersindo de. Minuta de un testamento. Librería de Victoriano Suárez, Imprenta Helénica, 1876

Binns, Niall. 'El escritor y su público. Del 'Discurso al alimón' al monólogo dramático (Lorca, Neruda, Parra)". Anales de Literatura Chilena, no. 12, 2009, pp. 65-84. . Ruiz, Javier y Cuadra, César. "Diálogos antipoéticos con Nicanor Parra”. Minerva. Revista del Círculo de Bellas Artes, no. 21. 2013, http://www.circulobellasartes.com/revistaminerva/articulo.php?id=551

Bolaño, Roberto. 2666. Vintage español, 2009.

Briz, Antonio (coord.). Saber hablar. Instituto Cervantes, Aguilar, 2008.

Cárdenas, María Teresa (ed.). Así habló Parra en El Mercurio. Aguilar, 2012.

Carrasco, Iván. Para leer a Nicanor Parra. Universidad Nacional Andrés Bello, 1999.

. "Discursos de sobremesa de Nicanor Parra y crisis del canon". Revista Chilena de Literatura, no. 62, 2003, pp. 5-23.

Cela, Camilo José. La familia de Pascual Duarte. Destino, 1955, p. 37 (1942).

Cervantes, Miguel de. Don Quijote de la Mancha II. Edición de John J. Allen. Cátedra, 1994. 
Chas Aguión, Antoni. "Los testamentos en la poesía de cancionero”. Revista de poética medieval, no. 16, 2006, pp. 53-78.

Derrida, Jacques. De la grammatologie. Les Editions de Minuit, 1967.

Espinoza Navarrete. Cristhian. "Diario de muerte de Enrique Lihn: la escritura sobre la línea de la muerte”. Estudios Filológicos, no. 35, 2000, pp.151166.

Gaché, Belén. Escrituras nómades. Ediciones Trea, 2006.

García de Diego, Pilar. "El testamento en la tradición popular. Testamentos de víctimas". Madrid: Revista de Dialectología y Tradiciones populares, no. 9, 1953, pp. 601-666.

Gumucio, Rafael. Nicanor Parra, rey y mendigo. Universidad Diego Portales, 2018.

Lihn, Enrique. Diario de muerte. Editorial Universitaria, 1989.

Neruda, Pablo; Parra, Nicanor. Discursos. Nascimento, 1962.

Palacio Valdés, Armando. Testamento literario. Librería de Victoriano Suárez, Imprenta Helénica, 1929.

Parra, Nicanor. Obras completas \& algo + (1935-1972). Galaxia Gutenberg, 2006. . After-dinner Declarations. Traducción de Dave Oliphant. Host Publications, 2009. . Obras completas \& algo + (1972-2006). II. Galaxia Gutenberg, 2011. . "La antipoesía no es un juego de salón”. En Juan Andrés Piña. Conversaciones con la poesía chilena. Pehuén, 1990, pp. 18-51.

Quezada, Jaime. Nicanor Parra tiene la palabra. Editorial Andrés Bello, 2007. . Nicanor Parra de cuerpo entero. Editorial Andrés Bello, 2007.

Ramírez, Sergio. "Un testamento literario". El boomerang. Blog literario en español. 26 sep 2012, http://www.elboomeran.com/blogpost/7/12652/sergio-ramirez/iun-testamento-literario/ 
Rodríguez, Mario. "Discursos de sobremesa: el francotirador pasa a la reserva (pero nunca se sabe si habla en serio o en broma)". En Nicanor Parra. Discursos de sobremesa. Cuadernos Atenea, 1997, pp. 5-18.

Rubio Árquez, Marcial. "Testamentos poéticos burlescos: hacia la definición de un subgénero literario popular”. En Pedro M. Cátedra García et al. La literatura popular impresa en España y en la América colonial: formas y temas, géneros, funciones, difusión, historia y teoría. SEMYR, 2006, pp. 241-251.

Soto, César. "Los libros de Nicanor Parra”. Estudios Públicos, no. 136, 2014, pp. 253-298.

Todorov, Tsvetan. Poética estructuralista. Traducción de Ricardo Pochtar. Losada, 2004.

Zerán, Faride. La guerrilla literaria. Huidobro, De Rokha, Neruda. Ediciones Bat. 1992. 